Emerging, Experimental and Current Topics Relevantto Technology in Counselor Education, Supervision and Practice

Journal of Technology in Counselor Education and Supervision (ISSN 2692-4192)

Volume 1(1): 3 -11

(C) 2021 Journal of Technology in Counselor Education and Supervision https://doi.org/10.22371/tces/001

\title{
A Content Analysis of Counseling Organizations' Social Media Usage
}

\author{
William B. McKibben'1 \& Sandra Logan-McKibben²
}

\begin{abstract}
Social media is a rapidly growing online platform for professional counselors and counseling organizations to communicate with the public, but little is known how counsleing organizations utilize social media. The authors content analyzed posts from nine ACA divisions' Facebook pages to explore how professional counseling organizations utilize social media to engage with outline followers. Sharing links to external websites was the most frequently occurring post but such postings were less likely to engage followers than sharing post, photo, or events from within Facebook or uploading a photo directly. Recommendations for counseling organizations to engage in effective social media practices are presented.
\end{abstract}

\section{Keywords}

social media, counseling, Facebook, technology, content analysis

Counselors have documented important practical and ethical considerations regarding social media usage at an individual level (e.g., privacy concerns, boundaries; ACA, 2014; Bratt, 2010; Brew, Cervantes, \& Shepherd, 2013; Giota \& Kleftaras, 2014; Mullen, Griffith, Greene, \& Lambie, 2014). However, researchers have paid less attention to the potential of social media as an outreach and communications platform at an organizational level. Many counseling organizations have a social media presence as a way to connect with followers online, but researchers have yet to investigate how counseling organizations utilize social media and how their utilization of social media engages followers online. This knowledge could optimize how counseling organizations promote and accomplish their mission via online communication with members, stakeholders, and the general public who follow the organizations on social media. In this study, we sought to begin addressing these needs by investigating what counseling organizations posted on their Facebook accounts and how this information engaged online followers.

Social media use among American adults has risen from 5\% in 2005 to $72 \%$ in 2019 (Pew Research

1 Nova Southeastern University, Fort Lauderdale, FL, USA

2 Florida International University, Miami, FL, USA
Center, 2019). In 2019, about $69 \%$ of American adults used Facebook, making it the most popularly used social media site compared to Instagram (37\%), Pinterest $(28 \%)$, Linkedln $(27 \%)$, Snapchat $(24 \%)$, Twitter (22\%), WhatsApp (20\%), and Reddit (11\%) (Perrin \& Anderson, 2019). Perrin and Anderson (2019) also reported that among social media platforms, Facebook tended to have the least pronounced differences in use among various age groups, and about $74 \%$ of Facebook users used the site daily. Among student counselors-in-training, Brew et al. (2013) reported that $92.9 \%$ of one sample $(\mathrm{N}=56)$ and $90.3 \%$ of a second sample $(\mathrm{N}=63)$ used social media, with $100 \%$ and $98.2 \%$, respectively, using Facebook. Notably, about $66 \%$ of Facebook users get news from the site, and $62 \%$ do so passively while looking for other things online (Pew Research Center, 2016). These news statistics are important given that newsfeeds across social media sites, including Facebook, use algorithms that provide users with stories based on what they react to (e.g., "like," "love"), which means that social media users are more likely to see stories from sources they have already engaged with in the past (DeMers,

Corresponding Author: William B. McKibben, PhD, Nova Southeastern University, 3301 College Ave. Fort Lauderdale, FL 33314. email: wmckibben@nova.edu 
2016). For professional counseling organizations that share updates and information with followers on Facebook, the likelihood that users will see the information in their newsfeeds may hinge, at least in part, on how often users engage with the organization to begin with by reacting to (e.g., clicking "like"), commenting on, and/or sharing its posts.

Whereas individual users typically create a personal Facebook account, businesses, organizations, or individuals attempting to brand themselves (e.g., musician, politician) usually create a Facebook page to market their products, services, or brands. Users can also create Facebook groups around a shared interest to which users can join or be added. Facebook allows users to share content in a variety of ways, such as posting a status update (i.e., text, hyperlinks to websites), uploading a photo, uploading a video or sharing live video (i.e., Facebook live), and sharing content from other Facebook users (including event pages created on Facebook). Facebook live has increased in popularity since 2016 , alongside increased mobile phone usage to access social media (DeMers, 2016). These interfaces offer a variety of options for connecting counselors to the public almost instantly.

\section{Social Media in Counseling}

Use of Facebook and other social media sites is scarcely discussed in counseling literature, and what does exist has focused almost exclusively on ethical considerations for individual counselors. For example, Bratt (2010) and Giota and Kleftaras (2014) discussed personal and professional relationships and boundaries, online self-disclosure, client and counselor privacy, and confidentiality as important ethical considerations for professional counselors to avoid causing harm to clients. The ACA Code of Ethics (2014) underscored these same issues, adding that they be addressed with clients as part of the informed consent process. The ACA Code of Ethics also specifies that professional counselors maintain separate personal and professional social media accounts. Brew et al. (2013) investigated professional counselors' social media use and found that $50 \%$ of sampled student counselors-in-training admitted to posting something to Facebook that they would not want a client to see, though an equal percentage of students reported using the strictest privacy settings on Facebook. The ethical discussions regarding social media are critical for professional counselors to navigate a rapidly changing technological landscape.

The opportunities that social media present for professional counselors are as numerous as the ethical considerations. For example, social media offers professional counselors opportunities to reach clients, potential clients, communities, other professional counselors and helping professionals, and stakeholders with shared interests in new and creative ways. For example, Mullen et al. (2014) noted that school counselors might use social media to share information quickly with students, families, and stakeholders. Giota and Kleftaras (2014) noted that counselors and psychologists might even utilize Facebook and other social media sites to screen clients and offer therapeutic services to those who might not otherwise be reached.

Counseling organizations and counselor education programs also might utilize Facebook to advance their mission and strategic plans. Tillman, Dinsmore, Chasek, and Hof (2013) noted that counselor education programs could harness the potential of social media to enhance recruitment, curricular, pedagogical, social, and alumni efforts. Currently, ACA and 19 of its 20 divisions have a Facebook page or group, which they use to communicate with professionals and the general public who follow them online. Organizational communication with followers through social media involves research, strategy, and ongoing evaluation in order to communicate effectively (Ledford, 2012), but there is virtually no research on organizational public engagement via social media in professional counseling. Namely, it is unclear what exactly ACA and its divisions use Facebook for or how effective their efforts are at engaging with followers online.

\section{Social Media Marketing and Strategic Outreach Efforts}

Social media has become a central outlet for companies to market their brands, products, and services. In an effort to understand marketing and communication strategies via social media, researchers across professional disciplines have content analyzed how organizations utilize social media to interface with online followers. McCorkindale (2010) content analyzed Facebook member and fan pages for the 2008 Fortune 50 companies and found that $80 \%$ of sampled companies did not regularly update their Facebook pages. Posts were more regularly made by employees, job seekers, customers, and journalists than by corporate representatives, but pages regularly contained photos $(65.5 \%)$, videos $(31 \%)$, and links to other websites (36\%) from the companies. In a similar study, Shen and Bissell (2013) content analyzed how six large beauty brands (e.g., Estée Lauder) used Facebook to promote brand awareness and loyalty. The authors found that the six brands all utilized text, photo, and video posting options on Facebook, and the brands particularly used question and answer posts and polls to engage with followers. Shen and Bissell (2013) extended their content analysis beyond McCorkindale's (2010) approach by exploring the extent to which Facebook posts predicted 
likes, comments, and shares from online followers. The authors found that although each brand had unique ways of achieving these engagements with Facebook followers, a Facebook survey was most likely to generate comments from users (likes and shares were not significantly different).

In contrast to for-profit companies, nonprofits tend to use social media for public relations and community outreach rather than product/service marketing (Lovejoy \& Saxon, 2012; Waters et al., 2009). Social media allows nonprofits to share their message and purpose directly with stakeholders and the public (Kim \& Um, 2016; Waters \& Lo, 2012) through strategies such as posting the organization's mission and purpose and advocating for their cause (Kelleher, 2006). Because professional counseling organizations such as ACA and its divisions are nonprofits, aligning their social media activities with strategies in the nonprofit sector may help maximize their online presence and accomplish their respective missions.

Researchers have investigated how nonprofits utilize social media to share information about their organization or cause with the public and with stakeholders. Waters et al. (2009) content analyzed 275 nonprofits' Facebook pages and found that over $70 \%$ of sampled organizations displayed at least one of the following: a description of the organization, names of administrators, links to the organizations' website, or an organizational logo. Organizations in this study also frequently used Facebook discussion boards (74\%), photo uploads (56\%), and links to external websites $(54 \%)$ to share information, while news announcement posts and videos were used less frequently $(<50 \%)$. In a similar study, Wallace, Wilson, and Miloch (2011) content analyzed National Collegiate Athletic Association (NCAA) and Big 12 athletic department Facebook pages and found that both associations posted status updates and links to external websites more often than uploading photos or videos, posting notes, or using other communication tools. Wallace et al. (2011) extended their investigation by examining group differences to observe how Facebook users interacted with NCAA and Big 12 pages. The authors found that Big 12 Facebook pages received significantly more likes and comments on their Facebook content than did NCAA pages. Although researchers have sought to understand social media use among for-profit and non-profit organizations, researchers in counseling have not conducted similar inquiries of counseling organizations.

\section{The Current Study}

Researchers who have studied social media strategies in the for-profit and nonprofit sectors have focused largely on Facebook, which is unsurprising given its ongoing popularity and usage over other social media sites. Additionally, researchers have consistently focused on the types of Facebook postings that organizations utilize (e.g., text, photo, video) and how effective these postings are at engaging online followers through posting reactions, comments and shares. Researchers have yet to apply similar research to professional counseling organizations, and such knowledge could help optimize how professional counseling organizations promote and accomplish their mission via online communication with members, stakeholders, and the general public who follow the organizations on social media. Thus, the purpose of the current study was to explore how counseling organizations utilize Facebook to engage with online followers. The study was guided by the following research questions: a) which types of Facebook posts do counseling organizations utilize, b) do the organizations differ in the types of Facebook postings made, c) do the organizations differ in the extent to which online followers engage with their Facebook content, and d) which types of Facebook posts engage online followers more frequently?

\section{Method}

We used content analysis to address our research questions. Because content analysis allows for contextualized examinations of communication (Krippendorf, 2013), it is a fitting method to evaluate how counseling organizations utilize social media to connect with online followers. We followed four guidelines from Krippendorf (2013) to conduct the content analysis: unitizing, sampling, recording, and reducing.

The unit of analysis was defined as a post to Facebook by a counseling organization. To sample units, we identified ACA divisions that had Facebook accounts. At the time of this study, 19 of 20 ACA divisions, as well as ACA, had a Facebook account. The Institutional Review Board determined material posted publicly on social media to be a form of publicly observable behavior and was therefore exempt from review, so we then contacted current Presidents of ACA and each ACA division to request permission to view their Facebook accounts for the purposes of this study. We were granted permission by 10 organizations, one declined permission, and nine did not respond to the initial or two follow-up email requests. Of the 10 who granted permission, one division's Facebook group was set to private, which prevented us from viewing the page. Both authors requested to join the organization's group, but we did not receive a response, leaving nine organizations' Facebook pages for analysis.

Neuendorf (2016) noted that at least 384 units are needed to generalize the results of a content analysis with a $95 \%$ confidence level. Also, to address research questions three and four, we calculated with $\mathrm{G}^{*}$ Power (Faul et al., 2007) that at least 116 units were needed 
to conduct a one-way multivariate analysis of variance (MANOVA) with a small effect size of .07 and power of .95. Based on these a priori power estimates, we aimed to code 45 postings from each of the nine sampled divisions to provide enough power to investigate all research questions. Because the sampled units were publicly posted on Facebook pages or groups, data were recorded as text, photos, and videos posted to the nine sampled divisions' Facebook pages/groups.

\section{Data Analysis}

For the content analysis, we reduced data into discrete categories in two ways. First, we coded data into a priori categories using a deductive approach (Krippendorf, 2013). The a priori categories were defined based on the functions available for posting to Facebook, which also relates to our first research question. For example, "type of post" was coded categorically as follows: text only $=1$, photo $=2$, video $=3$, link to a website $=4$, shared posting/photo/event within Facebook $=5$, and uploaded photo with an in-text link $=6$. We also recorded the number of Facebook reactions (e.g., "likes," "loves"), comments, and shares for each post. In tandem with the deductive approach, we employed an inductive coding approach that allowed new categories to emerge from the data. This allowed us to identify themes within the actual Facebook posts, thereby addressing research question one in more detail. Whereas we could clearly determine the Facebook functions available for use by the sampled organizations, we could not determine a priori what the organizations might actually share in their posts. The inductive approach allowed new themes to emerge and to be subsequently coded deductively.

Prior to coding, we developed a codebook and accompanying coding sheet in which we operationally defined each a priori variable and the coding procedure. We then conducted a pre-test by randomly selecting two Facebook accounts and five Facebook posts from each account to test the coding procedures in the codebook and to maximize discriminant validity and interrater reliability. After completing the pre-test together as a team, both authors independently coded the remaining posts from the nine sampled divisions. We met after coding each organization's Facebook page to compare codes and to come to consensus on any discrepancies. We documented all discrepancies and computed inter-rater reliability using ReCal 2 (Freelon, 2013). In this study, inter-rater reliability was excellent (99.1\% observed agreement; Krippendorff's $\alpha=.99$ ). The authors also reached consensus on all discrepancies throughout the coding process. We then used descriptive statistics (i.e., frequency counts) to describe the coded data, thereby detailing the types of Facebook posts that the sampled organizations utilized to engage with members (research question one).

To address research question two, we conducted a Chi-square analysis to investigate if the sampled organizations differed in what they posted to Facebook. We computed Cramer's $V$ to determine effect size. We also computed adjusted standardized residuals (ASRs) to determine which cells contributed most to the Chisquare (see Avent et al., 2015). ASR values \pm 1.96 indicated that an observed frequency fell above or below the expected frequency by three standard deviations and was thus considered statistically significantly different from the expected frequency; that is, that a type of Facebook post was utilized more or less frequently by an organization than expected.

Last, we conducted one-way MANOVAs to investigate organizational differences in Facebook reactions, comments and shares (research question three) and whether certain types of Facebook posts yielded more or less online follower engagement (research question four). "Organization" was entered as the independent variable for research question three (consisting of nine distinct categories), and "type of posting" was entered as independent variable for research question four (consisting of six distinct categories). For each MANOVA, Facebook reactions, comments, and shares were entered as continuous dependent variables to measure follower engagement with a Facebook post. Prior to running the MANOVAs, we identified and removed 14 multivariate outliers using Mahalanobis' distance (see Table 1). These outliers reflected Facebook postings with uncharacteristically high combinations of reactions, comments, or shares. With these outliers removed, $Q-Q$ plots still indicated that frequency counts for Facebook reactions and shares were positively skewed, violating the assumption of multivariate normality. To correct this, we performed a natural log transformation of the dependent variables, which improved Q-Q plots for Facebook reactions and shares to reflect a normal distribution. The assumption of linearity was supported by plots of standardized residuals, which indicated linear relationships among the three dependent variables to organization and type of Facebook post, respectively. None of the dependent variables correlated above .8 (see Table 1); thus, excessive multicollinearity was not a concern.

Results

\section{Organizations' Facebook Posts (RQ1)}

Across the nine organizations, we coded 403 Facebook posts. Sharing a link to a website was the most common post overall $(n=198,49.3 \%)$. Other posts included uploaded photos $(n=73,17.9 \%)$, shared postings/photos/events from other Facebook accounts ( $\mathrm{n}$ $=70,17.4 \%)$, text only ( $n=48,11.9 \%)$, and uploaded/ live video $(n=1,0.2 \%)$. A separate type of posting 
Table 1

Descriptive Data for Facebook Reactions, Comments, and Shares

\begin{tabular}{lcccc|cccc|ccc}
\hline & \multicolumn{3}{c|}{ Follower engagement descriptives } & \multicolumn{3}{c|}{$\begin{array}{c}\text { Multivariate outliers } \\
(N=14)\end{array}$} & \multicolumn{3}{c}{$\begin{array}{c}\text { Correlations } \\
(N=389)\end{array}$} \\
\cline { 2 - 12 } & Range & $M$ & $M d n$ & $S D$ & Range & $M$ & $M d n$ & $S D$ & Reactions & Comments & Shares \\
\hline Reactions & $0-73$ & 7.46 & 4 & 9.73 & $6-184$ & 70 & 65.5 & 51.07 & 1 & 1 \\
Comments & $0-3$ & .24 & 0 & .58 & $0-9$ & 2.64 & 2 & 2.71 & $.27^{* *}$ & 1 \\
Shares & $0-45$ & 1.36 & 0 & 4.72 & $0-167$ & 56.5 & 46 & 57.72 & $.67^{* *}$ & $.23^{* *}$ & 1 \\
\hline
\end{tabular}

Note. $\mathrm{M}=$ mean, $\mathrm{Mdn}=$ median, $\mathrm{SD}=$ standard deviation. ${ }^{* *} \mathrm{p}<.01$.

also emerged from the data, which we coded as "uploaded photo with an in-text link" ( $n=13,3.2 \%$, coded categorically as "6"). As noted previously, Facebook allows users to upload a photo and to enter text that is displayed with the photo. One division utilized this function by uploading a photo and including a link to a website in the text. Because this approach did not fit clearly into "uploaded photo" or "link to a website" categories, we created a separate category to capture these postings.

The number of reactions (e.g., likes, loves) that posts received ranged from zero to $184(\mathrm{M}=9.65, \mathrm{Mdn}=5$, $\mathrm{SD}=17.55)$. Comments on posts ranged from zero to nine $(\mathrm{M}=.32, \mathrm{Mdn}=0, \mathrm{SD}=.87)$, and shares of Facebook postings ranged from zero to $167(\mathrm{M}=$ $3.29, \mathrm{Mdn}=0, \mathrm{SD}=15.23$ ). As noted previously, we identified 14 multivariate outliers prior to conducting a MANOVA. These outliers contained four text only posts, four uploaded photos, three links to websites, and three shared postings/photos/events from other Facebook accounts (see Table 1).

Emergent themes. In addition to coding data into the a priori categories, several themes emerged from the data. Two clear themes that emerged across all posting types included the use of Facebook to promote organizational conferences and the use of hashtags. Sixty-three $(15.6 \%)$ posts explicitly referenced a conference, and 52 (12.9\%) posts contained at least one hashtag. An additional theme that emerged when organizations used "link to a website" and "uploaded photo with an in-text link" categories was the location to which Facebook followers were directed via the links. Specifically, $145(68.7 \%)$ of the 211 total website links directed followers to external websites unaffiliated with the counseling organization that shared the link (e.g., Huffington Post, npr.org). Forty (19\%) of the links directed followers to the respective organization's website, and $26(12.3 \%)$ of the shared links directed followers to another social media account hosted by the organization (e.g., Twitter).

\section{Organizational Differences in Posting Strategies (RQ2)}

Chi-square analysis indicated a significant relationship between the nine sampled organizations and the six categories of Facebook posts $[x 2(40, N=403)=$ 404.05, $p<.001]$. The calculated effect size showed a large effect (Cramer's $V=.45$ ). The ASRs indicated variability in how the sampled ACA divisions posted to the Facebook accounts (see Table 2). Text only postings occurred significantly above the expected value by organization \#1, whereas four organizations posted text only posts significantly below the expected value. Photos were uploaded significantly above the expected value by two organizations and significantly below the expected value by three organizations. Only one sampled organization posted their own video during the time frame of our study, making this post appear significantly above the expected value. Similarly, only one division utilized the strategy of uploading a photo with an in-text link, which made the organization's posts significantly above the expected value. Regarding links to websites, two organizations posted links significantly above the expected value, and three posted links significantly below the expected value. Finally, two organizations shared postings/photos/events from other Facebook pages significantly above the expected value, while five shared postings significantly below the expected value.

\section{Organizational Differences in Follower Engagement (RQ3)}

The MANOVA indicated a statistically significant difference in Facebook reactions, comments, and shares based on division $[\Lambda=.59, F(24,1096)=8.99, p<$ .001 , observed power $=1.00]$ that accounted for $16 \%$ of the variance (partial $\eta 2=.16$ ). Follow-up univariate analyses revealed that group differences significantly predicted all three dependent variables: Facebook reactions to a post $[F(8,380)=20.10, p<.001$, observed power $=1.00]$, comments on a post $[F(8,380)$ $=3.68, p<.001$, observed power $=.99$ ], and shares of a post $[F(8,380)=5.36, p<.001$, observed power $=1.00]$. Because we sought to protect anonymity of 
Table 2

Frequency Counts by Post Type

\begin{tabular}{|c|c|c|c|c|c|c|c|c|c|c|c|c|}
\hline & \multicolumn{2}{|c|}{$\begin{array}{c}\text { Text } \\
(N=48)\end{array}$} & \multicolumn{2}{|c|}{$\begin{array}{l}\text { Photo } \\
(\mathrm{N}=73)\end{array}$} & \multicolumn{2}{|c|}{$\begin{array}{l}\text { Video } \\
(N=1)\end{array}$} & \multicolumn{2}{|c|}{$\begin{array}{c}\text { Link } \\
(\mathrm{N}=198)\end{array}$} & \multicolumn{2}{|c|}{$\begin{array}{l}\text { Shared posting } \\
\qquad(N=70)\end{array}$} & \multicolumn{2}{|c|}{$\begin{array}{l}\text { Photo and link } \\
\qquad(\mathrm{N}=13)\end{array}$} \\
\hline & $\mathrm{n}$ & $A S R$ & $n$ & $A S R$ & $\mathrm{n}$ & $A S R$ & $n$ & $A S R$ & $\mathrm{n}$ & ASR & $\mathrm{n}$ & ASR \\
\hline Organization 1 & 20 & 7.5 & 7 & -0.6 & 0 & -0.3 & 16 & -1.5 & 0 & -3.1 & 0 & -1.3 \\
\hline Organization 2 & 8 & 1.3 & 6 & -0.8 & 0 & -0.4 & 8 & -4.5 & 23 & 6.3 & 0 & -1.3 \\
\hline Organization 3 & 0 & -2.6 & 28 & 8.2 & 0 & -0.4 & 15 & -2.3 & 2 & -2.4 & 0 & -1.3 \\
\hline Organization 4 & 4 & -0.7 & 17 & 3.7 & 0 & -0.4 & 6 & -5.1 & 18 & 4.2 & 0 & -1.3 \\
\hline Organization 5 & 8 & 1.3 & 1 & -2.9 & 0 & -0.4 & 20 & -0.7 & 3 & -2.0 & 13 & 10.3 \\
\hline Organization 6 & 1 & -2.1 & 0 & -3.3 & 0 & -0.4 & 44 & 6.9 & 0 & -3.3 & 0 & -1.3 \\
\hline Organization 7 & 7 & 0.8 & 4 & -1.7 & 0 & -0.4 & 22 & -0.1 & 12 & 1.7 & 0 & -1.3 \\
\hline Organization 8 & 0 & -2.6 & 0 & -3.3 & 0 & -0.4 & 44 & 6.9 & 1 & -2.9 & 0 & -1.3 \\
\hline Organization 9 & 0 & -2.6 & 10 & 0.8 & 1 & 2.8 & 23 & 0.3 & 11 & 1.3 & 0 & -1.3 \\
\hline
\end{tabular}

Note. Post Type: $x 2(40, N=403)=404.05, p<.001$, Cramer's V = .45.

the sampled organizations, we opted not to report detailed post hoc comparisons of mean score differences among the organizations.

Facebook Postings and Follower Engagement (RQ4) The MANOVA revealed a statistically significant difference in Facebook reactions, comments, and shares based on type of post $[\Lambda=.88, F(12,1008)=4.06, p$ $<.001$, observed power $=1.00$ ] that accounted for $4 \%$ of the variance (partial $\eta 2=.04$ ). Follow-up univariate analyses revealed that type of post significantly predicted reactions to the post $[F(4,383)=8.04, p$ $<.001$, observed power $=1.00]$, but comments $[F(4$, $383)=2.17, p=.07]$ and shares $[F(4,383)=1.45, p$ $=.22$ ] were not significant. Observed power for Facebook comments and shares in the univariate followups was .63 and .67, respectively. Post hoc comparisons for Facebook reactions using a Tukey HSD test indicated that mean scores for links to websites were significantly different from uploaded photos $(p<.01)$ and from shared postings/photos/events from another Facebook account $(p<.001)$. In other words, uploading a photo $(M=1.94)$ or sharing a post/photo/event from another Facebook account ( $M=2.12)$ was significantly more likely to yield higher Facebook reactions (e.g., clicking "like") compared to posting a link to a website $(M=1.49)$. There were no statistically significant mean score differences among text only posts and uploaded photos with an in-text link. The category for uploaded video was excluded from analysis because the category had fewer than two cases.

\section{Discussion}

The purpose of this study was to systematically investigate what ACA and its divisions post on Facebook to connect with members and stakeholders. Using content analysis, we found that sampled ACA divisions posted links to websites most often overall, followed by uploaded photos, shared postings/photos/events from other Facebook accounts, text only, uploaded photos with a link, and uploaded/live video, respectively. Links more commonly directed online followers to websites unaffiliated with the counseling division, though some links directed followers to either a division's website or separate social media account (e.g., Twitter). The frequency at which sampled ACA divisions posted links to websites reflects a similar pattern identified in Wallace et al.'s (2011) content analysis of NCAA and Big 10 Facebook pages.

About $13 \%$ of sampled Facebook posts also used a hashtag with the post. A hashtag is a word or phrase marked by a pound sign (e.g., \#counseling, \#advocacy) that turns the phrase into a searchable link (Facebook, 2017). If a Facebook user were to search for a hashtag phrase, any public posts that include the hashtag, regardless of who posted it, would be included in the search results. Hashtags can be a particularly useful tool for ACA divisions to drive online users to content. For example, we also found that nearly $16 \%$ of posts were about a division's conference. If a division were to post multiple times leading up to, during, and after a conference, then using a hashtag for each post (e.g., \#Division2020) would allow online followers to locate all conference-related posts with one searchable term. Similarly, divisions might use hashtags around a specific topic or initiative, either within or across multiple divisions (e.g., \#wellness, \#Professionalldentity). As divisions consider intentional public outreach strategies, hashtags can be a useful approach to connect stakeholders and the public to information about ACA divisions.

In this study, links to websites were posted most 
often, but this type of post was less likely to elicit reactions from followers. Rather, sharing a post, photo, or event from within Facebook or uploading a photo directly, both of which were done less frequently than posting links, were more likely to garner reactions compared to posting a link to a website. An important takeaway from this finding is that directing Facebook followers to information not directly affiliated with the division may not be as effective at engaging followers compared to strategies that showcase the division. Key functions of social media public relations in the nonprofit sector include sharing an organization's purpose, mission, and core messages with stakeholders and the public (Kelleher, 2006; Kim \& Um, 2016; Waters \& Lo, 2012). Our findings support that showcasing a counseling division with photos or sharing posts, photos, or events from other divisions are more likely to engage followers.

Notably, the type of Facebook posting had a very small effect in predicting reactions (4\%), indicating that although there were statistically significant differences in Facebook reactions based on type of post, other variables likely also account for variations in reactions. One of these additional variables identified in this study was the organizations themselves. That is, some organizations' Facebook posts were more likely to receive reactions, comments, or shares in general than others. This finding aligns with Wallace et al.'s (2011) investigation into NCAA and Big 10 Facebook pages. Some organizations may have had more followers and/or a more established presence on Facebook than others, which could have yielded more online follower interaction.

Finally, we found that sampled organizations differed in the types of postings they utilized, and this too might account for the group differences observed in follower engagement. For example, it is possible that organizations who posted more photos were also more likely to engage followers. Shen and Bissell (2013) found that major beauty brands tended to rely on their own unique posting strategies to foster brand loyalty on Facebook, which aligns with our findings that certain counseling organizations were more or less likely to utilize a certain type of Facebook post. It is possible that these individual differences in posting strategies appeal to the online followers of the respective organizations Facebook pages, which in turn yields more online follower interaction.

\section{Limitations}

The findings from this study should be considered in light of several limitations. First, we did not document how many followers or members that a page or group had at the time of coding. Related, although we sampled an equal number of Facebook posts from each organization, we did not account for the frequency at which organizations posted on Facebook within a discrete period of time (e.g., how many posts per week or month). This additional information would have provided better context in understanding the audience and overall level of activity of the organizations, and it is likely that some organizations are more active on Facebook than others, which may be an additional factor in follower engagement. Also, although the sampled units yielded enough power to generalize the content analysis findings and the MANOVA results, we observed low power for Facebook comments and shares in the univariate follow-ups to the MANOVA addressing posting type. This stemmed from variability in which the types of Facebook postings were utilized by the sampled divisions. For example, only one video was uploaded across all 403 coded postings. The low power observed in these two particular follow-up analyses could have resulted in type II error, particularly for comments, as it was approaching statistical significance.

We focused this study on ACA division Facebook accounts. Thus, the results may not generalize to other professional counseling and counseling-related organizations. Similarly, the nonprofit structure and goals of ACA divisions may not align with the goals of individual counselors or for-profit counseling agencies trying to market services to the public. Finally, we only studied Facebook, and there are a variety of other social media platforms that have features similar to and unique from Facebook. Some sampled organizations in this study had more than one social media presence, so our results may not generalize to social media usage on other platforms.

\section{Implications and Future Directions}

Based on the findings, we recommend that ACA divisions display a description of the organization, names of leaders, a link to the organization's website, and an organizational logo. Further, utilizing photos and videos to engage followers in getting to know the organization's activities, members, and leaders might boost interaction with the organization's social media content. For example, once a new business year has begun, an organization could post a video message from the incoming president. Posting photos of all newly elected leaders could also garner engagement from followers. Relatedly, organizations could utilize social media to provide updates about meetings and decisions that affected the organization and its members. The one video we coded in this study was a Facebook live video of a division's conference lunch hour. The video allowed online followers to watch award presentations, speeches from divisional leaders, and the announcement of the next year's conference location. This is one example of an exemplary use of 
Facebook live to connect with stakeholders in particular. We recommend that ACA divisions consider how video and Facebook live can bring their organizations to life by showcasing events, initiatives, and members in real time.

Nonprofits are particularly poised to engage followers online because their causes may be easier to relate to compared to product and service brands (Bernritter, Verlegh, \& Smit, 2016). Accordingly, ACA divisions, and counseling organizations more broadly, should consider how to utilize Facebook in a way that maximizes the relatability of their cause. If an organization shares a link to a website, for example, we encourage the organization to also include text that clearly communicates the meaning or relevance for the content being shared. Although driving people to websites unaffiliated with a counseling organization is not inherently negative, follower engagement might be optimized if people understand how external information fits within the organization's purpose or mission. Presumably, all ACA divisions share some core values, so it would make sense for divisions to share one another's content. Corson (2016) provided useful strategies that counseling organizations could utilize, including making the name matter, closely moderating the Facebook page, and promoting member communication. One way that counseling organizations might promote member communication is to ask members periodically to introduce themselves or to share their favorite counseling resource or website.

An important step for counseling organizations who utilize social media is to engage in a strategic planning process to develop a clear public relations strategy that accurately portrays their appropriate professional identity. Leadership teams might consider questions such as: a) Why are we on Facebook? b) What is/are our primary goal(s) for our Facebook page? c) Are we currently using social media to advance our organization's mission? If not, what changes do we need to make to better advance our mission online? If so, how can we maintain or further enhance our mission through social media? d) Who is our target audience on social media? e) Are we reaching our target audience through social media? How do we know? How can we do better? One possibility is that counseling organizations might host opportunities for leaders to attend workshops focused on effective strategies for, and uses of, social media.

Whereas this study examined the organizational side of Facebook use, additional research is needed to study those who like and follow professional counseling organizations. Ledford (2012) noted that a critical factor in social media marketing is knowing one's audience, which can be achieved through research into the audience's social media use (e.g., audience's preferences with social media platforms, trends in use) and the audience's understanding of the organization and its message. By surveying its members, ACA and its divisions, as well as other professional counseling organizations with a Facebook presence, may benefit from learning about follower's Facebook use (e.g., how often they access Facebook, how often do they see posts from the organization). Obtaining demographic information could help organizations understand who is following them on Facebook and to better understand where they could invest efforts in increasing followers. Asking followers what they expect and/or want to see posted by the organization could help optimize information delivery in alignment with an organization's goals. Notably, Facebook allows a page administrator to see who has liked the page; thus, any counselor, agency, or organization has access to the names of their followers. By researching and understanding the followers of a Facebook page, posts can be matched to how the intended audience uses social media and understands the messages being communicated online (Ledford, 2012).

\section{Conclusion}

This study provided preliminary evidence into how ACA divisions utilize Facebook to stimulate follower engagement. Despite varied uses of Facebook across divisions, we found that not all posts generated follower engagement. Thus, we recommend that divisions use strategies to showcase the organization and its activities over simply distributing information that may or may not be related to the organization directly. Newer Facebook features such as polling questions, events, and Facebook live may allow counseling organizations to understand members' preferences while also engaging followers with social media content. Finally, although this study examined organizational use of Facebook, the findings may also prove relevant to counseling practitioners or agencies seeking to build or maintain a professional online presence.

\section{References}

American Counseling Association. (2014). 2014 ACA code of ethics. Author.

Avent, J. R., Wahesh, E., Purgason, L. L., Borders, L. D., \& Mobley, A. K. (2015). A content analysis of peer feedback in triadic supervision. Counselor Education and Supervision, 54(1), 68-80. https://doi. org/10.1002/j.1556-6978.2015.00071.x

Bernritter, S. F., Verlegh, P. W., \& Smit, E. G. (2016). Why nonprofits are easier to endorse on social media: The roles of warmth and brand symbolism. Journal of Interactive Marketing, 33, 27-42. https://doi.org/10.1016/j. 
intmar.2015.10.002

Bratt, W. (2010). Ethical considerations of social networking for counsellors. Canadian Journal of Counselling and Psychotherapy, 44(4), 335-345.

Brew, L., Cervantes, J. M., \& Shepard, D. (2013). Millennial counselors and the ethical use of Facebook. Professional Counselor, 3(2), 93-104.

Corson, W. (2016). Nonprofit news: Building a community on social media. Retrieved from http://ct.counseling.org/2016/10/ nonprofit-news-building-community-social-media/.

DeMers, J. (2016). The top 7 social media trends that dominated 2016. Retrieved from https://www.forbes.com/sites/ jaysondemers/2016/12/07/the-top-7-social-media-trendsthat-dominated-2016/\#7fef2c44726c.

Facebook. (2017). How do I use hashtags? Retrieved from https://www.facebook.com/help/587836257914341.

Faul, F., Erdfelder, E., Lang, A. G., \& Buchner, A. (2007). $G^{*}$ Power 3: A flexible statistical power analysis program for the social, behavioral, and biomedical sciences. Behavior Research Methods, 39, 175-191. https://doi. org/10.3758/BF03193146

Freelon, D. (2013). ReCal OIR: Ordinal, interval, and ratio intercoder reliability as a web service. International Journal of Internet Science, 8(1), 10-16.

Giota, K. G., \& Klaftaras, G. (2014). Social media and counseling: Opportunities, risks, and ethical considerations. International Journal of Social, Behavioral, Educational, Economic, Business and Industrial Engineering, 8, 2378-2380.

Kelleher, T. (2006). Public relations online: Lasting concepts for changing media. Sage.

Kim, S. \& Um, N. (2016). Recognition in social media for supporting a cause: Involvement and self-efficacy as moderators. Social Behavior and Personality, 44(11), 18631878. https://doi.org/10.2224/sbp.2016.44.11.1863

Krippendorff, K. (2013). Content analysis: An introduction to its methodology (3rd ed.). Sage.

Ledford, C. J .W. (2012). Changing channels: A theory-based guide to selecting traditional, new, and social media in strategic social marketing. Social Marketing Quarterly, 18(3), 175-186. https://doi. org/10.1177\%2F1524500412460671

Lovejoy, K., \& Saxton, G. D. (2012). Information, community, and action: How nonprofit organizations use social media. Journal of Computer-Mediated Communication, 17(3), 337-353. https://doi. org/10.1111/j.1083-6101.2012.01576.x

McCorkindale, T. (2010). Can you see the writing on my wall? A content analysis of the Fortune 50's Facebook social networking sites. Public Relations Journal, 4(3), 1-13.

Mullen, P. R., Griffith, C., Greene, J. H., \& Lambie, G. W. (2014). Social media and professional school counselors: Ethical and legal considerations. Journal of School Counseling, 12(8), 1-38.
Neuendorf, K. A. (2016). The content analysis guidebook (2nd ed.). Sage.

Perrin, A., \& Anderson, M. (2019). Share of U.S. adults using social media, including Facebook, is mostly unchanged since 2018. Retrieved from https://www.pewresearch.org/ fact-tank/2019/04/10/share-of-u-s-adults-using-social-media-including-facebook-is-mostly-unchanged-since-2018/

Pew Research Center. (2016). News use across social media platforms 2016. Retrieved from http://www.journalism.org/2016/05/26/ news-use-across-social-media-platforms-2016/.

Pew Research Center. (2019). Social media fact sheet. Retrieved from https://www.pewresearch.org/internet/ fact-sheet/social-media/

Shen, B., \& Bissell, K. (2013). Social media, social me: A content analysis of beauty companies' use of Facebook in marketing and branding. Journal of Promotion Management, 19(5), 629-651. https://doi.org/10.1080/1049 6491.2013.829160

Tillman, D. R., Dinsmore, C. L., Chasek, C. L., \& Hof, D. D. (2013). The use of social media in counselor education. In Ideas and research you can use: VISTAS 2013. Retrieved from http://www.counseling.org/knowledge-center/ vistas.

Wallace, L., Wilson, J., \& Miloch, K. (2011). Sporting Facebook: A content analysis of NCAA organizational sports pages and Big 12 conference athletic department pages. International Journal of Sport Communication, 4(4), 422444. https://doi.org/10.1123/ijsc.4.4.422

Waters, R. D., Burnett, E., Lamm, A., \& Lucas, J. (2009). Engaging stakeholders through social networking: How nonprofit organizations are using Facebook. Public Relations Review, 35(2), 102-106. https://doi.org/10.1016/j. pubrev.2009.01.006

Waters, R. D., \& Lo, K. D. (2012). Exploring the impact of culture in the social media sphere: A content analysis of nonprofit organizations' use of Facebook. Journal of Intercultural Communication Research, 41(3), 297-319. https://doi.org/10.1080/17475759.2012.72877 